\title{
Initial Bilingual Development: One Language or Two?
}

\author{
Lihong Du \\ International School, Changjiang Professional College \\ No. 918 Xiongchu Avenue, Wuhan 430074, China \\ Tel: 86-27-8717-0151_E-mail: joanna18@163.com
}

\begin{abstract}
It is claimed that bilingual children have two separate linguistic systems from early ages. Over the past decades, linguists carried out a number of studies to test the validity of the claim. They explored bilingual children's code-mixing in correlation with a variety of linguistic elements, such as lexicon, syntax, phonology in different contexts, concluding that bilingual children had separate linguistic system for each language. Although there were certain limitations in these studies, most of their results supported the statement.
\end{abstract}

Keywords: Bilingual children, Language mixing, Code switching, One language system

\section{Introduction}

Bilingual first language acquisition refers to the situation that individuals are exposed to two or more languages before age three (McLaughlin, 1984, p.73). In this essay, bilinguals refer to individuals who are exposed to two languages from birth.

There is a debate among researchers about whether bilingual children are initially bilingual or not and that they are monolingual before they are three years old, that is, they have to pass a 'fusion' stage, when they couldn't distinguish between their two language systems (Volterra \& Taeschner, 1978). In other words, the researchers disagree about how many linguistic systems bilingual children have, a unitary linguistic system or dual language system.

It is necessary to distinguish between two definitions first, language-mixing and code-switching in order to investigate whether bilingual children have two separate language systems from early age. Language-mixing, sometimes is called code-mixing, is used to describe well-known phenomenon that almost all bilingual children use language elements (phonological, lexical, syntactic, etc.) from two languages in the same utterance or conversation. This situation normally happens during a very early stage of language acquisition when bilingual children are about two years old. It was believed that language-mixing happens because bilingual children don't have the ability to differentiate the two languages yet (Koppe \& Meisel, 1995, p.277). Code-switching, refers to a certain skill of proficient bilingual speakers, that is, their ability to select the correct language according to such external factors as the interlocutor, the situational context, the topic of the conversation, etc (Koppe \& Meisel, 1995, p.277).

The characteristics of child bilingual code-mixing during the earliest stage of productive language use, therefore, is different from adult bilingual code-switching in structure and function (Genesee, 2003; Redlinger \& Park, 1980). When bilingual children code-mix, they may violate syntactic or pragmatic constraints on code-switching established by their bilingual community. The violations of bilingual children are often considered as a failure in distinguishing between the two linguistic systems on the level of grammatical or pragmatic competence. Some linguists claimed that bilingual code-mixing provided evidence for bilingual children having only one language system at this stage (Koppe \& Meisel, 1995, p.277).

Investigators explored bilingual children's code-mixing in correlation with a variety of linguistic elements, discovering that bilingual children had separate linguistic system for each language. More specifically, they could differentiate between their two languages in lexicon, syntax, phonology, and they could choose appropriate language according to language context, though, bilingual children did code-mix (Genesee, Nicoladis \& Paradis, 1995; Quay, 1995; Meisel, 2000; Paradis, 2001; Genesee, Nicoladis \& Paradis, 1995; Genesee, Boivin \& Nicoladis, 1996).

This essay will look at a number of relevant studies first, then comparing these studies on their methodology, subjects, findings and conclusions and giving a final conclusion. 


\section{Language Mixing}

\subsection{Volterra and Taeschner 1978 study}

Volterra and Taeschner conducted a study to investigate the stages that a child passed in the process of simultaneous acquisition of two languages and the strategies the child used to learn two languages (Volterra \& Taeschner, 1978, p.311).

The data was collected through monthly recordings of thirty minutes' simultaneous speech of two Italian-German bilingual sisters, Lisa and Giulia. The sisters were observed from $1 ; 5$ to $3 ; 6$ and $1 ; 2$ to $2 ; 6$ respectively. Their parents claimed to use one parent one language policy in the family, that is, they only used their native language to address their two daughters. The recordings were transcribed including everything said by the two sisters and the adults present.

The results showed that subjects passed through mainly three stages to acquire two languages in early childhood.

\subsubsection{The first stage}

At this stage, in children's lexical system, a word in one language rarely had a corresponding word in the other language with the same meaning. Bilingual children tended to take some words which were not corresponding in adult speech as correspondent to each other. They used one language or the other depending on what they wanted to say, but not on the language spoken to them, so Volterra and Taeschner maintained that it was difficult to make any conclusions concerning their syntactic systems (Volterra \& Taeschner, 1978, pp.312-317).

\subsubsection{The second stage}

At the second stage, the children reached the point where they could master two lexical systems. That is, they could name objects or events using different words from two languages and they could translate one language into the other. They used words belong to the same language in one utterance and their choices depended on whom they were speaking to. However, they haven't had two separate syntactic systems yet, they used the same syntactic rules with different lexical systems (Volterra \& Taeschner, 1978, pp.317-324).

\subsubsection{The third stage}

In this phase, the process of bilingual learning was finished. The subjects could apply two systems of syntactic rules to different lexicon from two languages. This process was difficult because the data showed many examples of interference on the syntactic level and this stage lasted for quite a long time. This phenomenon normally occurred when the children had to switch quickly from one language to the other because they were talking with interlocutors speaking different languages. To minimize the rate of interference, the children had to keep the two languages apart. Under such circumstances, the children normally labeled one person with one language because this strategy could make the choice of the vocabulary and syntax easier for them (Volterra \& Taeschner, 1978, pp.324-326).

\subsection{Redlinger and Park 1980 study}

Redlinger and Park focused that investigating the degree of language mixing of bilingual children could help to judge whether bilingual children had only one language system at the early stage of language acquisition or not. In addition, they pointed out three main limitations of previous studies which dealt with language mixing of bilingual children. First, the previous investigators didn't analyze the relationship between language mixing and language development in terms of age. Second, previous arguments were based on examples instead of specific distributional data. Third, in most studies, frequencies of substituted words were reported in tokens, rather than in types. Redlinger and Park argued that frequency in tokens had misled the results to some extent, for young children often use the same repeated utterances in different situations (Redlinger \& Park, 1980, pp.337-338).

Considering these methodological difficulties, Redlinger and Park carried out a study to investigate language mixing with respect to language development. In their study, language mixing involved the insertion of a single element or of a partial or entire phrase from one language into an utterance of the other language (Redlinger \& Park, 1980, p.340).

There were four subjects involved in this study, Henrik $(2 ; 4.8)$, Marc $(2 ; 8.19)$, Marcus $(2 ; 0.1)$ and Danny (1;11.22). They all had German fathers. Henrik and Marc were French/German bilinguals, Marcus Spanish/German bilingual and Danny English/German bilingual. The information of language use in the family was provided by the mothers. Redlinger collected thirty to forty-five minutes of taped simultaneous speech of the four children about every three weeks over several months and she transcribed the tape within three days following a home visit. The percentage of language mixing occurring in certain period was calculated on type utterances (Redlinger \& Park, 1980, pp.339-340). 
The results demonstrated that Henrik and Marc whose languages were more advanced produced fewer mixed utterances than Marcus and Danny. Overall, the mixing rates of the four children decreased with the language development. Redlinger \& Park suggested that the high mixing rates during the earliest period reflected the subjects' inability to differentiate the two languages and the decreased mixing rate implied that the subjects were in a gradual process of language differentiation (Redlinger \& Park, 1980, pp.340-344). The researchers then concluded that bilingual children had only one language system at the initial stage.

After analyzing the distribution of the categories of the lexical substitutions, the investigators discovered that nouns were the most frequent word category substituted by children, and more function words were substituted than content words in general (Redlinger \& Park, 1980, pp.345-349).

\section{Lexical system}

Quay (1995) pointed out one methodological drawback of previous studies in claiming bilingual children could not differentiate between their two languages, that is, they ignored the factor that whether bilingual children had the lexical resources to make a choice (Quay, 1995, pp.369-371). The researcher also questioned the Principle of Contrast, which stated as an absence of synonym in early lexical development. In other words, translation equivalents didn't exist at the earliest stage of bilingual development (Quay, 1995, p.371).

Quay suggested that bilingual children had two separate lexical systems at the very beginning of their language development and they could distinguish between the two languages (Quay, 1995, pp.613-615).

In order to test the hypothesis, Quay studied the language development of a Spanish-English bilingual infant, Manuela, from birth to $1 ; 10$. The data consisted of sixty video recordings and daily diary records. The video recordings were aimed two half hours every week, one half hour when Manuela interacted with her Spanish-speaking father (Spanish context), the other half hour with her English-speaking grandmother (English context). Manuela played with same toys or books in the two half hours (Quay, 1995, p.373).

After analyzing the transcripts of the recordings and the diary, Quay found that Manuela had a total vocabulary of 300 words (i.e. productive lexicon) including 54 pairs of equivalent words at age 1;10 (Quay, 1995, p.376). In this study, equivalent pairs referred to a pair of words which had the same general meaning and could substitute each other in a wide range of contexts (Quay, 1995, p.384).

Furthermore, Manuela produced nine pairs of equivalent words in the first six months of speech (from $0 ; 11$ to $1 ; 5)$. The claim that Manuela had Equivalent vocabulary referred to the situation that she interchangeably used one of the two crosslinguistic synonyms to name the same object or process (Quay, 1995, p.378). The equivalents in one language for her first nine pairs of synonyms occurred only 19 days after she learned the vocabulary in the other language. She used Spanish words to interact with her father, and the English equivalents with her grandmother (Quay, 1995, p.380).

Quay concluded that Manuela had lexical resources to choose between two languages and she could use appropriate vocabulary to interact with interlocutors who speak different languages from the earliest stage of language development. Thus, Quay argued it is almost impossible to determine the boundary between the first stage and the second stage claimed by Volterra and Taeschner in their 1978 study (Quay, 1995, pp.380-381).

\section{Syntactic system}

Meisel held that the evidence provided by previous studies was not sufficient to support the hypothesis that bilingual children passed through a syntactic mixing stage before they attained two separate systems of syntactic rules. On one hand, the researchers should only consider different grammar aspects of two target adult languages, that is, comparing bilingual children's production of different syntactic rules. On the other hand, the phenomenon that bilingual subjects tended to use the wrong syntactic structures in the earlier phase was probably due to the dominant language influence (Meisel, 2000, pp.328-331).

The subjects were two French-German bilingual children, a girl and a boy. They both were French dominant. The video recordings of their free interaction with their parents were taken every two weeks from 1;0 to 4;0 (Meisel, 2000, pp.333-334). Meisel transcribed the recordings and worked out the subjects' acquisition process of French and German syntactic rules respectively. Two grammar points were focused in this study, word order and subject-verb agreement.

After comparing the discovered acquisition process with monolingual acquisition process, Meisel discovered that the two subjects' word order was less variable than that of monolinguals and SVO (i.e. subject verb object) word order was predominant in both languages, which diverged from the case of monolingual children. They used different word order in both languages as soon as they began to produce multi-word utterances. Furthermore, 
they acquired verb inflection at the very early stage almost without errors within a short period of time. Due to the fact that the function of early verb inflection was to encode subject-verb agreement, Meisel suggested that bilingual children would not mix subject verb agreement rules in two languages (Meisel, 2000, pp.336-340).

Meisel then concluded that bilingual children didn't go through a phase of one syntactic system before they could differentiate two syntactic systems (Meisel, 2000, p.342).

\section{Phonological system}

Paradis focused on two methodological limitations of relevant previous studies: one was that these studies looked at single case of children acquiring different language pairs, but making generalizations to all of the situations; the other was that none of the prior studies had compared bilingual children's phonology production with that of monolingual children (Paradis, 2001, p.20).

So as to address these methodological weaknesses, Paradis included a comparatively larger group of participants, 18 English-speaking and French-speaking monolingual children, and 17 French-English bilingual children living in Quebec, Canada, to test whether bilingual children had separate phonological systems at the earlier stage of bilingual acquisition (two years old) and whether their two systems influenced each other (Paradis, 2001, pp.20-21).

The subjects were asked to repeat a number of nonsense words created according to phonological constraints in each language with the assistance of French and English native speakers (Paradis, 2001, p.25). A phonological development phenomenon, word truncation was focused in this experiment. Word truncation referred to the phenomenon that young children often omitted some of the syllables when they learn to produce polysyllabic or multi-syllabic words (Paradis, 2001, p.22). The monolingual children were tested in separate rooms in their daycare centers and the bilingual children were tested in their homes with their parents present to ensure they were in the familiar bilingual contexts (Paradis, 2001, p.26). The performance of the bilingual group was compared with two monolingual groups to investigate whether there were cross-linguistic effects in bilingual's phonological system (Paradis, 2001, pp.26-28).

The results demonstrated that both monolingual and bilingual groups exhibited language specific sensitivity effects (i.e. pronounced the nonsense words obeying the phonological rules) for French words, but only English monolingual children show that sensitivity for English words. Paradis suggested that bilingual children's truncation of English WS'WS (W stands for weak, and S for strong) words was influenced by French pronunciation rules (Paradis, 2001, p.33).

Thus, Paradis concluded that bilingual children had two different phonological systems, their separate systems, however, appeared to influence each other. In addition, the investigator suggested the direction of crosslinguistic effects found in this study (from French to English) was probably due to individual language dominance of the bilingual subjects (Paradis, 2001, pp.34-35).

Similarly, Watson, after reviewing the main findings in previous literature, maintained that monolingual children did have two separate phonetic systems, but which were different in some way from those of monolinguals. Furthermore, Watson claimed that bilingual children must pass through a mixed stage with respect to phonological production before they could differentiate the two systems (Watson, 1991, pp.44-45).

\section{Language context}

Genesee, Boivin and Nicoladis conducted a research in 1996 to explore whether two-year-old bilingual children could correctly use different languages with different monolingual interlocutors who were strangers. Their subjects were French-English bilingual children.

The results indicated that bilingual children had the ability to identify the language characteristics of the strangers with minimal exposure. Although the language spoken by the strangers were the less proficient languages of most of the children, children used more of the strangers' languages with the strangers than with their parents who could speak the same languages as the strangers. Also, they used strangers' language as much as they could and minimized their use of the other language not known by the strangers (Genesee et al, 1996, p.435).

The researchers didn't find a statistically reliable link between children's code-mixing rates and their parents' discourse styles (Genesee et al, 1996, p.434). Undoubtedly, the results provided evidence for children having two separate language systems. 


\section{Mixing rate}

\subsection{Goodz 1994 study}

Goodz claimed that bilingual children acquired two languages in different situations, like exposure type, sociolinguistic environments, etc. For example, sometimes the two languages which children were exposed to were spoken by people in the surrounding neighborhood whereas in other cases, only one of the two languages was spoken in the community outside the family (Goodz, 1994, p.64).

In order to investigate the extent of language mixing and the cause of language mixing in the process of the language development of bilingual children, Goodz studied the acquisition process of thirteen French-English bilingual children. The children were from 13 to 15 months old at the beginning of the study. All families used one parent one language policy. The language samples were collected through audio-taping the naturalistic interaction between the father and the child and the mother and the child every six weeks over a three to four years period. At the same time, a bilingual investigator kept a written record of the children's utterances as well as detailed notes of the contexts of the interactions (Goodz, 1994, pp.65-66).

The data showed some language mixing in the spontaneous utterances of all of the subjects (Goodz, 1994, p.66). Furthermore, language mixing, different from previous reports, increased gradually over the period of experiment, peaked at 2;7 to $3 ; 0$. Goodz suggested that their high rate of language mixing was due to the wish to express complex thoughts but lacking the necessary vocabulary in the language being used at the time of mixing (Goodz, 1994, p.67). Goodz argued that such evidence, as requesting equivalents in the language that was not being used in a current conversation and using French pronunciation when introducing an English lexical item into a French utterance indicated that children were aware of the differences in the language systems (Goodz, 1994, pp.67-68).

The results demonstrated that mothers tended to use their non-native languages when they responded to their children's language behavior, while fathers often translated children's non-native utterances (Goodz, 1994, pp.73-74). Goodz claimed that the maintenance of parent language separation was not a crucial factor in affecting children differentiating between two languages and what was more important was that parents encouraged their children to actively participate in conversations in various contexts (Goodz, 1994, pp.77-78).

\subsection{Genesee, Nicoladis and Paradis 1995 study}

Genesee et al concentrated on investigating how early in the development of bilingual acquisition that bilingual children's ability of differentiating two languages was present. Genesee suggested that evidence of bilingual children speaking each language to interlocutors of that language without being influenced by the interlocutors' mixing rates would challenge the dual language system hypothesis. They also tested the effect of children's language dominance and parents' mixing rate on language mixing of bilingual children (Genesee et al, 1995, pp.611-613).

The researchers noticed that children used one- or two-word structures most of the time instead of complex syntactic structures. Therefore, Genesee et al enlarged the definition of language mixing to include one-word stage mixing across utterances, that is, inter-utterance mixing (Genesee et al, 1995, pp.612-620).

They examined the language use of five French-English bilingual children with each parent separately and parents together. The researchers expected to see children using more mixed utterances with both parents present. In this way, they would observe whether or not and to what degree children could differentiate their two languages since three families used one parent one language rule and the other two used mixed languages when speaking to the children (Genesee et al, 1995, pp.614-616). 45 to 60 minutes video- and audio-taped recordings were taken on three different occasions within three weeks, one with father alone, one with mother, and the third with both parents present. The parents were told that code switching was acceptable (Genesee et al, 1995, pp.618-619).

The results showed that four children obviously used more English with their mothers than with their fathers and more French with their fathers than with their mothers in all three sessions (Genesee et al, 1995, pp.622-623). Furthermore, the data didn't exhibit a correlation between parents' and children's mixing rates (Genesee et al, 1995, p.623).

After eight months of the previous visit, they tested children's ability to choose appropriate language in strange linguistic contexts through observing two children playing with a monolingual English-speaking stranger (Genesee et al, 1995, p.613). The researchers recorded children's conversation with the stranger and with their mothers alone or their fathers alone a second time, then comparing three different conversations. Genesee et al found although both children did more language mixing when talking to the stranger than to their parents, they 
used more English-only utterances than French-only utterances or mixed utterances with the stranger (Genesee et al, 1995, pp.623-624).

Genesee et al then claimed that these findings indicated that the children could differentiate between their two languages in both familiar and unfamiliar language contexts.

After exploring the relationship between language dominance of the subjects and their mixed utterances patterns, the researchers found that language dominance played a role in children's language mixing. More specifically, the children tended to use more mixed utterances when using their non-dominant language than when using their dominant language. Furthermore, Genesee et al gave an explanation other than lack of the ability of differentiating two languages for code-mixing: the bilingual children used all available linguistic resources to express themselves (Genesee et al, 1995, pp.619-629). Genesee claimed that the results provided evidence for children differentiating two language systems (Genesee, 1989, p.166).

\subsection{Comeau, Genesee and Lapaquette 2003 study}

This study aimed to test Modeling Hypothesis, which stated as bilingual children were sensitive to the rates of bilingual code mixing in the input and they would model their output in accordance with the input addressed to them (Comeau, 2003, p.114).

The most frequent mixing form reported in former studies was lexicon. Lexical mixing in this study referred to the use of at least one word from both languages (i.e. French and English in this study) in the same utterances (Comeau et al, 2003, p.113).

Six French-English bilingual children were included in this study. The average age of the children is 2;4 at the time of the first recording. All of the parents stated that they use one parent one language policy when speaking to their children.

The children's interaction with their father and mother when playing freely with toys was video-taped and audio-taped separately. Based on these recordings, the researchers estimated children's development in each language. The analyses indicated that four children were more advanced in English, the other two in French (Comeau et al, 2003, pp.117-118).

Following the parental sessions, the researchers recorded the interactions between the children and one of two research assistants approximately 30-45 minutes during three separate family visits. Children's less developed language was used predominantly in the conversation. By doing so, the researchers expected to see maximum rates of code mixing (Comeau et al, 2003, pp.118-119). The assistants varied their code mixing rates from relatively low (15\%) to relatively high (40\%), and back to relatively low (15\%) in three sessions (Comeau et al, 2003, p.119).

The analyses demonstrated that assistants' use of a mixed utterance was more often followed by a mixed utterance than a non-mixed utterance of the children (Comeau et al, 2003, p.123). By comparing children's mixing rates in three sessions, the researchers discovered that all of the children increased their mixing rates in session 2 (i.e. the high-mixing rate session) and five of the six subjects decreased their mixing rate in session 3. In addition, the children demonstrated their ability in matching language choice to that of interlocutors. The researchers claimed that the increase from session 1 to session 2 could not simply be attributed to familiarity with the assistant (Comeau et al, 2003, pp.123-125).

Comeau et al concluded that children were sensitive to the change of overall code mixing rates by the assistants and they adjusted their mixing rates accordingly (Comeau et al, 2003, pp.123-124). They suggested that their results reinforced the view that young bilingual children were able to differentiate their two languages pragmatically (Comeau et al, 2003, p.125).

\section{Discussion and conclusion}

All of the studies reviewed in this essay used similar methodology, analyzing the recordings of bilingual children's conversation with different interlocutors, father alone, mother alone, both parents together, or stranger alone.

Nevertheless, there are considerable differences among those studies.

First of all, the results of seven out of nine studies indicated that bilingual children didn't pass a one-language-system stage, and the children could differentiate between their two language systems from the very beginning of their language production; whereas the findings of the other two studies (i.e. Volterra \& Taeschner, 1978; Redlinger \& Park, 1980) were in accordance with the unitary linguistic system hypothesis. 
Second, the seven studies whose findings ran counter to the unitary language system hypothesis looked at one specific linguistic aspect of children's language mixing, such as lexicon, syntax, phonology, language context, mixing rate, while the other two studies only dealt with code mixing in general.

Third, the bilingual children involved in these studies were at different ages (their ages ranged from birth to $2 ; 8$ ). The researchers considered these different ages as initial stage, and they investigated children's language development over different period of time (ranging from several months to 4 years), most of their findings, however, confirmed the dual language system hypothesis.

In addition, three studies (i.e. Goodz, 1994; Genesee et al, 1995; Genesee et al, 1996) claimed no correlation between parents' mixing rate and children's mixing rate, whereas the findings of Comeau et al (2003) study demonstrated that bilingual children changed their mixing rate in accordance with that of the interlocutors.

Finally, Redlinger \& Park (1980) concluded that more advanced bilingual children used considerably less mixed utterances. Adversely, Goodz (1994) discovered that his subjects' code mixing rate increased over the language development, peaked at 2;7 to 3;0.

On the other hand, there are a number of limitations in these studies.

To begin with, one limitation of most studies is that the investigators only looked at language production of a small group of bilingual children, normally 2 to 6 children involved in each study. As Paradis (2001) argued, this was not a sufficient sample size, but the researchers generalized their findings to all of the bilingual children's language development.

Second, as Goodz (1994) pointed out, bilingual children acquired two languages in different sociolinguistic environments, this could affect their language development. Most of the studies, however, didn't take account of sociolinguistic factors. The subjects in Volterra and Taeschner (1978) study were two sisters who were brought up in the exactly same linguistic environment. If the investigators could compare two sisters' language development at same age, they would likely get different results.

Third, the language pairs of the children in each study were different, which could affect the results of the studies. Some languages were probably very similar to each other, thus, it was comparatively more difficult for children to distinguish them.

Furthermore, only a small portion of the studies reviewed in this essay considered quality of input, that is, whether parents strictly adhered to one parent one language policy when addressing to their children.

Last but not least, the studies were carried out at different time, which might have accounted for different results of the studies.

In conclusion, taking account of the differences among these studies stated above and the drawbacks of these studies, it was difficult to decide whether bilingual children had to pass a fused stage at which they had unitary linguistic system, though, most of the studies supported the dual language system hypothesis. Future studies could enlarge the sample size, examining children's language development over a long period of time, including different language pairs, and concentrating on more linguistic variables.

\section{References}

Comeau, L., Genesee, F. and Lapaquette, L. (2003). The Modeling Hypothesis and Child Bilingual Codemixing. The International Journal of Bilingualism, 7(2), 113-126.

Genesee, F. (1989). Early Bilingual Development: One Language or Two? Journal of Child Language, 16, 161-175.

Genesee, F. (2003). Rethinking Bilingual Acquisition. In J.M. Dewaele, A. Housen, \& L. Wei (Eds.) Bilingualism: Beyond Basic Principles. Clevedon: Multilingual Matters Ltd, pp. 204-228.

Genesee, F., Boivin, I. and Nicoladis, E. (1996). Talking with Strangers: A Study of Bilingual Children's Communicative Competence. Applied Psycholinguistics, 17, 427-442.

Genesee, F., Nicoladis, E. and Paradis, J. (1995). Language Differentiation in Early Bilingual Development. Journal of Child Language, 22, 611-631.

Goodz, N.S. (1994). Interactions between Parents and Children in Bilingual Families. In F. Genesee, \& J. C. Richard (Eds.) Educating Second Language Children. Cambridge University Press, pp. 61-81.

Koppe, R. and Meisel, J. M. (1995). Code-mixing in Bilingual First Language Acquisition. In L. Milroy, \& P. Muysken. (Eds.) One Speaker, Two Languages: Cross-disciplinary Perspectives on Code-switching. Cambridge 
University Press, pp. 276-301.

McLaughlin, B. (1984). Second Language Acquisition inn Childhood. I. Preschool Children. Hillsdale, N. J.: Lawrence Erlbaum, p. 73.

Meisel, M. (2000). Early Differentiation of Language in Bilingual Children. In W. Li (ed.) The Bilingual Reader. London: Routledge, pp. 328-343.

Paradis, J. (2001). Do Bilingual Two-year-olds Have Separate Phonological System? The International Journal of Bilingualism, 5(1), 19-38.

Quay, S. (1995). The Bilingual Lexicon: Implications for Studies of Language Choice. Journal of Child Language, 22, 369-387.

Redlinger, W. and Park, T. Z. (1980). Language Mixing in Young Bilinguals. Journal of Child Language, 7 , 337-352.

Volterra, V. and Taeschner, T. (1978). The Acquisition and Development of Language by Bilingual Children. Journal of Child Language, 5, 311-326.

Watson, I. (1991). Phonological Processing in Two Languages. In E. Bialystok (ed.) Language Processing in Bilingual Children. Cambridge University Press, pp. 25-48. 